\title{
Exploring susceptibility measures to persuasion
}

\author{
No Author Given \\ No Institute Given
}

\begin{abstract}
There is increasing evidence that indicates how personalising persuasive strategies may increase the effectiveness of persuasive technologies and behaviour change interventions. This has led to a wide range of studies exploring susceptibility to persuasion which highlight the role of individual differences. Measuring susceptibility to persuasion, while accounting for individual differences can be challenging, particularly where persuasive strategies may be considered similar due to their underlying components. In this paper, we present a study exploring susceptibility to Cialdini's principles of persuasion with a focus on how we can distinguish susceptibility measures between the most recently identified Unity principle and Social proof. This study was conducted using an online survey incorporating susceptibility measures to all seven Cialdini principles and a measure of the actual effectiveness of seven corresponding persuasive strategies. Our results indicate that while we are able to distinguish susceptibility measures between Unity and Social proof, together with Commitment, Scarcity and Reciprocity, we were unable to obtain these with susceptibility measures for Liking and Authority.
\end{abstract}

Keywords: Susceptibility·Persuasion·Influence·Personalisation

\section{Introduction}

Persuasive technologies and behaviour change interventions are often designed to apply personalised persuasive strategies to increase their effectiveness for encouraging individuals to change their behaviour $[16,19,13,4,18,2,21,27]$. This partly motivated by the results from recent studies that report how the effectiveness of persuasive strategies can vary based on individual differences such as age, gender, culture, personality and other cognitive measures $[25,44,30,6,29,40,12]$. As such, personalising persuasive strategies is desirable as applying those which are unsuitable or inappropriate may limit an interventions' effectiveness and or result in demotivating individuals to perform a desired target behaviour $[17,22,1,36,24]$.

Measuring individuals' susceptibility to different persuasive strategies can help to provide an insight into what strategies are most suitable and likely to be effective. However, this may be challenging particularly for scenarios where there may be underlying similarities between the persuasive strategies being considered for deployment.

Amongst the variety of persuasion and influence techniques available, persuasive technologies and behaviour change intervention are often designed to apply persuasive strategies based on Cialdini's [5] principles of persuasion. Recently, the original set of six principles was extended to incorporate a newly identified seventh principle, Unity. The principle of Unity suggests that an individual's behaviour may be influenced by reference to shared identities, the individual may consider themselves to be a member 
of, together with others. As such, persuasive strategies developed from the principle of Unity, can leverage the concepts of acting together and being together to influence behaviour [5,38,39,37]. This is comparable to the Granfalloon influence technique, which emphasises the individual's categorical and group membership association, to influence attitudes, beliefs and behaviour [33, 42].

Prior to the definition of Unity, the principle of Social proof suggests that an individual's behaviour may be influenced by the observation of others', whose actions and behaviour may be considered as correct, suitable and appropriate by the individual. While Social proof is distinguishable from Unity, both share a common underlying social component, namely the reference to the behaviour of others. The distinction between both lies in how Unity draws upon reference to the shared identities of the individual, which is absent from Social proof and may be considered to rely upon a broader and less specific social context. However, given the underlying similarities between both principles, assessing susceptibility for either simultaneously may be challenging, due to the potential overlap between strategies developed from these principles.

In this paper, we report our findings from an exploratory study of susceptibility measures to Cialdini's [5] principles of persuasion. The aim of this study was to discover how to distinguish measures of susceptibility to Unity and Social proof and whether this can be achieved together with measures of susceptibility to the remaining five Cialdini principles. In section 2 we briefly review previous work concerning susceptibility measures for Cialdini principles and we outline the methodology of our study in section 3. The results of the study are reported in section 4 and finally we review these findings and outline our future work in Section 5.

\section{Related work}

Table 1 lists all seven Cialdini [5] principles of persuasion, together with a summary on how these may be used to influence behaviour. The susceptibility to persuasion scale [17] (STPS) provides a means of measuring susceptibility to the original six Cialdini [5] principles of persuasion, (excluding Unity). By measuring susceptibility to different persuasive strategies, it is possible to personalise strategies by identifying which are most likely to be effective in addition to those which may be counterproductive and unsuitable for a given audience [17]. The effectiveness of the STPS has been demonstrated in a longitudinal study of actual effectiveness; where susceptibility measures acquired through the STPS, was used to personalise persuasive strategies that proved to be more effective in reducing individuals eating between meals compared to those who did not receive personalised persuasive strategies [17]. The STPS has been applied in studies investigating differences and similarities in susceptibility to persuasion between nationalities [28], differences based on cultures [23], language [3] in addition to measuring susceptibility to persuasive strategies designed to increase physical activity for individuals with chronic obstructive pulmonary disease [43] and in predicting susceptibility to phishing emails [32]. In this paper, we build upon this existing work through an exploratory study designed to discover how we can distinguish susceptibility measures between the most recently identified Unity principle and Social proof in addition to how these can be obtained together with susceptibility measures for all other Cialdini [5] principles of persuasion. 
Table 1. Cialdini's principles of persuasion and how these may be applied to influence behaviour [5]

\begin{tabular}{|l|l|}
\hline Principle of persuasion & Summary \\
\hline Reciprocity & $\begin{array}{l}\text { We are likely to respond in kind as the receiving party in } \\
\text { an exchange out of a sense of obligation to do so }\end{array}$ \\
\hline Commitment and Consistency & $\begin{array}{l}\text { We aim to be consistent in our actions and decision to avoid } \\
\text { complexity arising from inconsistencies in our behaviour }\end{array}$ \\
\hline Social Proof & $\begin{array}{l}\text { Our actions beliefs and behaviours may be strongly influenced } \\
\text { by what we observe in others as correct and / or appropriate }\end{array}$ \\
\hline Liking & $\begin{array}{l}\text { We may be significantly influenced by what is attractive and } \\
\text { appealing to us }\end{array}$ \\
\hline Authority & $\begin{array}{l}\text { We will often accept the beliefs and attitudes of those we } \\
\text { consider to be within a position of expertise }\end{array}$ \\
\hline Scarcity & We are strongly influenced to avoid loss \\
\hline Unity & $\begin{array}{l}\text { Reference to shared identities we define ourselves as a member } \\
\text { of together with others can strongly influence our behaviour }\end{array}$ \\
\hline
\end{tabular}

\section{Methodology}

We measured susceptibility to all seven Cialdini [5] principles using a survey that consisted of three sections and recruited participants from Amazon mechanical turk (MT). The first section captured participants' details including gender, age and location.

The second section consisted of 46 question statements, with participant required to indicate their level of agreement using a seven item Likert scale ranging from strongly disagree to strongly agree. These questions included all 32 questions used to develop the original STPS scale as described in [17] in addition to 10 questions designed to measure susceptibility to the Unity principle. We also included four attention check questions where participants were provided to respond as instructed e.g. please select strongly disagree for this statement. All 46 questions were displayed randomly, in 11 sets of four and one set of two. After responding to all questions, participants were provided with the opportunity to provide feedback on the study.

In the final section of the survey, participants were presented with a randomly selected persuasive messages (based on one of the seven Cialdini [5] principles) which encouraged them to complete an optional ten item short personality inventory (TIPI) [10]. We included this section to provide a measure of actual effectiveness which could be used to discover to what extent, susceptibility measures corresponded with participants choosing to complete the TIPI test.

Table 2: Survey questions including those designed to measure susceptibility to Unity, STPS questions and attention checks.

\begin{tabular}{|l|l|l|}
\hline Principle & Principle ID & Question statement \\
\hline & Unity1 & Community is vital, we are all here for each other. \\
\cline { 2 - 3 } & Unity2 & $\begin{array}{l}\text { When we are faced with a challenge my colleagues and } \\
\text { I work together to find a solution. }\end{array}$ \\
\cline { 2 - 3 } & Unity3 & $\begin{array}{l}\text { I am proud to be a member of the community and they } \\
\text { are proud of me. }\end{array}$ \\
\cline { 2 - 3 } & &
\end{tabular}


Table 2 continued from previous page

\begin{tabular}{|c|c|c|}
\hline Principle & Principle ID & Question statement \\
\hline & Unity4 & $\begin{array}{l}\text { My social network is close we try to help each other as } \\
\text { much as we can. }\end{array}$ \\
\hline & Unity5 & $\begin{array}{l}\text { When faced with a decision I choose to do what is best } \\
\text { for the team because this is also the best for me. }\end{array}$ \\
\hline & Unity6 & $\begin{array}{l}\text { I celebrate the achievements of others within my social } \\
\text { network. }\end{array}$ \\
\hline & Unity7 & $\begin{array}{l}\text { I am more inclined towards suggestions from my } \\
\text { community compared to those from others. }\end{array}$ \\
\hline & Unity8 & $\begin{array}{l}\text { Together my colleagues and I consider the outcomes of } \\
\text { our actions for each other. before we agree what to do. }\end{array}$ \\
\hline & Unity9 & I value recommendations from my social network. \\
\hline & Unity10 & $\begin{array}{l}\text { It is more important for me to be liked by my colleagues } \\
\text { than my boss. }\end{array}$ \\
\hline \multirow{5}{*}{ Reciprocity } & Reciprocity11 & $\begin{array}{l}\text { When a family member does me a favour I am very } \\
\text { inclined to return this favour. }\end{array}$ \\
\hline & Reciprocity12 & I always pay back a favour. \\
\hline & Reciprocity13 & $\begin{array}{l}\text { If someone does something for me I try to do something } \\
\text { of similar value to repay the favour. }\end{array}$ \\
\hline & Reciprocity14 & When I receive a gift I feel obliged to return a gift. \\
\hline & Reciprocity15 & $\begin{array}{l}\text { When someone helps me with my work I try to pay them } \\
\text { back. }\end{array}$ \\
\hline \multirow{5}{*}{ Scarcity } & Scarcity16 & $\begin{array}{l}\text { I believe rare products (scarce) are more valuable than } \\
\text { mass products. }\end{array}$ \\
\hline & Scarcity17 & $\begin{array}{l}\text { When my favourite shop is about to close I would visit } \\
\text { it since it is my last chance. }\end{array}$ \\
\hline & Scarcity18 & $\begin{array}{l}\text { I would feel good if I was the last person to be able to } \\
\text { buy something. }\end{array}$ \\
\hline & Scarcity19 & $\begin{array}{l}\text { When my favourite shampoo is almost out of stock I } \\
\text { buy two bottles. }\end{array}$ \\
\hline & Scarcity20 & Products that are hard to get represent a special value. \\
\hline \multirow{6}{*}{ Authority } & Authority21 & I always follow advice from my general practitioner. \\
\hline & Authority22 & $\begin{array}{l}\text { When a professor tells me something I tend to believe } \\
\text { it is true. }\end{array}$ \\
\hline & Authority23 & I am very inclined to listen to authority figures. \\
\hline & Authority24 & I always obey directions from my superiors. \\
\hline & Authority25 & $\begin{array}{l}\text { I am more inclined to listen to an authority figure than } \\
\text { a peer. }\end{array}$ \\
\hline & Authority26 & I am more likely to do something if told than when asked. \\
\hline \multirow{5}{*}{ Commitment } & Commitment27 & $\begin{array}{l}\text { Whenever I commit to an appointment I always follow } \\
\text { through. }\end{array}$ \\
\hline & Commitment28. & I try to do everything I have promised to do. \\
\hline & Commitment29 & $\begin{array}{l}\text { When I make plans I commit to them by writing them } \\
\text { down. }\end{array}$ \\
\hline & Commitment30 & $\begin{array}{l}\text { Telling friends about my future plans helps me to carry } \\
\text { them out. }\end{array}$ \\
\hline & & Once I have committed to do something I will surely do it. \\
\hline
\end{tabular}


Table 2 continued from previous page

\begin{tabular}{|c|c|c|}
\hline Principle & Principle ID & Question statement \\
\hline & Commitment3 & If I miss an appointment I always make it up. \\
\hline \multirow{5}{*}{ Social proof } & Social proof33 & $\begin{array}{l}\text { If someone from my social network notifies me about } \\
\text { a good book I tend to read it. }\end{array}$ \\
\hline & Social proof34 & $\begin{array}{l}\text { When I am in a new situation I look at others to see } \\
\text { what I should do. }\end{array}$ \\
\hline & Social proof35 & $\begin{array}{l}\text { I will do something as long as I know there are others } \\
\text { doing it too. }\end{array}$ \\
\hline & Social proof36 & I often rely on other people to know what I should do. \\
\hline & Social proof37 & It is important to me to fit in. \\
\hline \multirow{5}{*}{ Liking } & Liking38 & I accept advice from my social network. \\
\hline & Liking39 & $\begin{array}{l}\text { When I like someone I am more inclined to believe him } \\
\text { or her. }\end{array}$ \\
\hline & Liking40 & I will do a favour for people that I like. \\
\hline & Liking41 & $\begin{array}{l}\text { The opinions of friends are more important than the } \\
\text { opinions of others. }\end{array}$ \\
\hline & Liking42 & If I am unsure I will usually side with someone I like. \\
\hline \multirow{4}{*}{$\begin{array}{l}\text { Attention } \\
\text { checks }\end{array}$} & Attention1 & Please select Strongly agree for this statement. \\
\hline & Attention2 & Please select Strongly disagree for this statement. \\
\hline & Attention3 & Please select Strongly agree for this statement. \\
\hline & Attention4 & Please select Strongly disagree for this statement. \\
\hline
\end{tabular}

Table 3. Persuasive messages designed to encourage participants to complete the TIPI test.

\begin{tabular}{|l|l|}
\hline Principle & Persuasive message \\
\hline Unity & $\begin{array}{l}\text { Please join your, fellow participants by completing the following short } \\
\text { personality test }\end{array}$ \\
\hline Social proof & $\begin{array}{l}\text { We would like to invite you to complete a short personality test. The majority } \\
\text { of participants, have also completed this part of the study. }\end{array}$ \\
\hline Reciprocity & $\begin{array}{l}\text { We will shortly process and approve your responses to this HIT. Meanwhile, } \\
\text { please consider completing the following short personality test. }\end{array}$ \\
\hline Commitment & $\begin{array}{l}\text { As part of your agreement to participate in this study, we would like to invite } \\
\text { you to complete a short personality test. }\end{array}$ \\
\hline Liking & $\begin{array}{l}\text { We hope you have enjoyed participating with our study and would like to } \\
\text { invite you to complete a short personality test. }\end{array}$ \\
\hline Authority & $\begin{array}{l}\text { We recommend completing the following short personality test to further } \\
\text { support the research objectives of our study. }\end{array}$ \\
\hline Scarcity & $\begin{array}{l}\text { We would like to invite you complete a short personality test. This is the last } \\
\text { opportunity for you to contribute towards our research on social influence } \\
\text { and persuasion. }\end{array}$ \\
\hline
\end{tabular}




\section{Results}

To be eligible to participate in our study, participants were required to have a $95 \%$ acceptance rate (indication of previous work completed on MT considered to be of good quality) and be based in either the UK, USA or Canada. 320 participants completed the survey, 302 of which provided valid responses to the attention check questions. The final sample used in our analysis consisted of $\approx 40 \%$ female, $\approx 59 \%$ male, $\approx 1 \%$ preferred not to indicate their gender, $\approx 1 \%$ aged $18-19, \approx 24 \%$ aged $20-29, \approx 42 \%$ aged $30-39, \approx 16 \%$ aged $40-49, \approx 12 \%$ aged $50-59$ and $\approx 5 \%$ aged 60 or more. $\approx 98 \%$ of participants were based on the USA and $\approx 2 \%$ were based in Canada. $\approx 13 \%$ of participants received the Authority persuasive message, $\approx 12 \%$ Commitment, $\approx 15 \%$ Liking, $\approx 19 \%$ Reciprocity, $\approx 10 \%$ Scarcity, $\approx 17 \%$ Social proof and $\approx 13 \%$ Unity. $\approx 53 \%$ of participants completed the TIPI test, $\approx 47 \%$ did not.

\subsection{Analysis of susceptibility measures}

To discover whether our survey provided a means of distinguishing susceptibility to Unity and Social proof, together with other Cialdini [5] principles, we conducted an exploratory factor analysis using principal component analysis (PCA). We used this approach to discover whether latent variables within the study data could be identified as Cialdini [5] principles and to discover whether participants' reported susceptibility corresponded with measures of actual effectiveness.

As participant responses were captured using an ordinal scale, we created a polychoric correlation matrix from participant responses (to susceptibility questions) as suggested by [31]. Reviewing the correlation matrix revealed that all 42 susceptibility question responses correlated with others with at least $r=.3$. The Kaiser-Meyer-Olkin test measure of sampling adequacy was 0.93 and Bartlett's test of sphericity was significant $\left(\chi^{2}=(861, N=302)=6560.346, p<.001\right)$.

To determine the number of components to extract, we used parallel analysis (PA) [14] and Velcier's minimum average partial (MAP) test [41]. Results from these tests conflicted, with PA suggesting four components to retain and MAP suggesting five. Interpretation of the scree plot was inconclusive, given the potential for multiple inflexions. As suggested by [26], we investigated both four and five component solutions, which we deemed to be overly complex due to multiple high and low cross loadings of susceptibility questions across all components. We anticipated that this was likely due to the presence of redundant questions within both solutions resulting with increased complexity and consequently difficult to interpret. To resolve these issues, we used an iterative exploratory approach to identify which questions were most relevant to which component and which could be considered as redundant. To achieve this we used the following process.

We first set the number of components to extract based on the number of principles our survey was designed to measure. This is considered suitable given positive results reported in prior studies using questions included in our study [11]. Secondly, components would only be considered for extraction based on the latent root or Kaiser's criterion [15]. This is considered suitable provided the sample size is greater than 250 , the average communality of the questions is greater than or equal to .6 [7] and when the number of variables included in the analysis is between 20 and 50 [11]. Thirdly, only stable components would be retained; that is components with a minimum of three strong loadings of at least .5 as these may be considered to be practically significant for developing a 
solution [20,34,26,11]. Finally, a component solution would only be considered suitable provided all components were considered interpretable and demonstrated an optimal structure whereby responses for questions load highly on a single component only and may be considered conceptually related to that component. Solutions produced in our iterative exploratory analysis were required to meet all of these conditions.

A preliminary analysis revealed seven components within the data which matches the number of principles our survey was designed to measure and each component met the latent root criteria of eigenvalues greater than one. Together these factors accounted for $59 \%$ of the variance. To improve interpretation of these components, we repeated the analysis using Oblimin rotation with seven components specified for extraction. To further improve interpretation and structural clarity of the seven components, questions with low primary loadings and or high cross loadings were removed individually and the component solution respecified (using a polychoric correlation matrix excluding values from questions removed). Questions removed from the initial seven component solutions included Unity 10 and Social proof 23 and this respecified solution accounted for $60 \%$ of the variance.

Upon removing Social proof 23, the seventh component was reduced below the latent root criteria and therefore was respecified to six components, which accounted for $59 \%$ of the variance. All five Liking related questions were removed from the six component solution due to high cross loading, none of which loaded onto a single component that could be considered as stable for the Liking principle. This resulted with increasing the cumulative variance the six component solution accounted for to $60 \%$. We continued our exploratory process of removing questions individually from the six component solution considered as redundant. These included Authority 12, Commitment 20, Scarcity 7, Authority 11, Unity 7, Unity 2, Reciprocity 2, Authority 16 and Commitment 19.

Upon removing Commitment 19 from the six component solution, the sixth component was reduced below the latent root criteria and as such was removed, together with all Authority related questions, as these did not contribute to a stable component for this principle due to multiple high and low cross loading. The initial five component solution accounted for $64 \%$ of the variance, which after removing Scarcity 7, increased to $65 \%$. The five components were labelled as Unity, Commitment, Social proof (social proof), Reciprocity and Scarcity.

A reliability analysis was performed to assess the consistency of the questions retained for measuring susceptibility to the five Cialdini principles identified from our analysis. Following suggestions from $[8,45,9]$ we calculated the ordinal $\alpha$ coefficient using a polychoric correlation matrix from the subset of retained questions for each component of the five component solution. The results indicate good reliability for Unity, Commitment, Social proof and Reciprocity and acceptable for Scarcity.

\subsection{Analysis of actual effectiveness and susceptibility}

We used a $\chi^{2}$ test to investigate the actual effectiveness of the seven strategies listed in Table 3 for encouraging participants to complete the TIPI test. Results suggest that there is an overall significant difference in the distribution of actual effectiveness across all strategies: $\chi^{2}=(302,6)=16.811, p=.01, V=.236$. However, there was no significant difference in the distribution of actual effectiveness for any of the strategies based on participants' gen$\operatorname{der}\left(\chi^{2}=(302,2)=2.307, p=.31, V=.08\right)$ or age $\left(\chi^{2}=(302,5)=3.14, p=.67, V=.1\right)$. This suggests overall, that the persuasive strategies differ in actual effectiveness, but these differences are not related to individual differences of age and gender between participants. 
Table 4. Five component solution loadings with Oblimin rotation and Ordinal $\alpha$ for each component. Primary component loadings are shown in bold.

\begin{tabular}{|l|l|l|l|l|l|}
\cline { 2 - 6 } \multicolumn{1}{c|}{} & \multicolumn{3}{c|}{ Components labelled as Cialdini Principles } \\
\hline Question Id & Unity & Commitment & Social proof & Reciprocity & Scarcity \\
\hline Unity1 & $\mathbf{0 . 7 3}$ & 0.06 & -0.01 & 0.15 & -0.08 \\
\hline Unity3 & $\mathbf{0 . 7 3}$ & 0.00 & 0.07 & 0.01 & 0.09 \\
\hline Unity4 & $\mathbf{0 . 8 3}$ & -0.05 & -0.01 & 0.02 & 0.07 \\
\hline Unity5 & $\mathbf{0 . 6 0}$ & 0.08 & 0.12 & -0.03 & 0.06 \\
\hline Unity6 & $\mathbf{0 . 8 8}$ & 0.01 & -0.12 & -0.05 & -0.07 \\
\hline Unity8 & $\mathbf{0 . 5 6}$ & 0.25 & 0.10 & 0.01 & 0.04 \\
\hline Unity9 & $\mathbf{0 . 6 5}$ & -0.07 & 0.23 & 0.09 & 0.06 \\
\hline Reciprocity1 & -0.05 & 0.07 & -0.05 & $\mathbf{0 . 8 2}$ & 0.01 \\
\hline Reciprocity3 & 0.07 & 0.09 & -0.05 & $\mathbf{0 . 7 8}$ & -0.01 \\
\hline Reciprocity4 & -0.02 & -0.12 & 0.18 & $\mathbf{0 . 7 7}$ & 0.10 \\
\hline Reciprocity5 & 0.14 & 0.08 & -0.04 & $\mathbf{0 . 7 5}$ & 0.01 \\
\hline Scarcity6 & 0.01 & 0.05 & -0.13 & 0.08 & $\mathbf{0 . 8 7}$ \\
\hline Scarcity8 & 0.02 & 0.09 & 0.29 & -0.15 & $\mathbf{0 . 5 8}$ \\
\hline Scarcity10 & 0.02 & -0.07 & 0.05 & 0.02 & $\mathbf{0 . 8 5}$ \\
\hline Commitment17 & 0.00 & $\mathbf{0 . 8 6}$ & 0.02 & 0.00 & 0.02 \\
\hline Commitment18 & -0.02 & $\mathbf{0 . 7 4}$ & -0.07 & 0.12 & -0.05 \\
\hline Commitment21 & 0.12 & $\mathbf{0 . 7 9}$ & -0.07 & -0.10 & 0.07 \\
\hline Commitment22 & -0.04 & $\mathbf{0 . 7 4}$ & 0.16 & 0.14 & -0.01 \\
\hline Social proof24 & 0.00 & 0.10 & $\mathbf{0 . 7 3}$ & 0.13 & 0.05 \\
\hline Social proof25 & 0.01 & -0.02 & $\mathbf{0 . 7 9}$ & 0.02 & 0.00 \\
\hline Social proof26 & 0.03 & -0.12 & $\mathbf{0 . 8 1}$ & -0.07 & -0.07 \\
\hline Social proof27 & 0.10 & 0.10 & $\mathbf{0 . 7 1}$ & -0.02 & 0.09 \\
\hline Eigenvalues & 4.0 & 2.85 & 2.75 & 2.79 & 2.04 \\
\hline \% of variance & 18 & 13 & 12 & 12 & 9 \\
\hline$\alpha$ & .89 & .89 & .8 & .84 & .73 \\
\hline
\end{tabular}

We further investigated the actual effectiveness of the strategies and participant responses to susceptibility to persuasion questions, to discover whether there was any significant difference in susceptibility and the actual effectiveness of the strategies. To achieve this, we calculated composite susceptibility scores using the median of participant responses for each set of susceptibility questions, for each component of the PCA model (as listed in Table 4). We then compared the distribution of the susceptibility scores for each component of the PCA model, and the actual effectiveness of the corresponding strategy. This was measured in terms of whether participants were persuaded to complete the TIPI test or did not (for each strategy). To perform this analysis, we used a MannWhitney $\mathrm{U}$ test which is suitable for comparing the distribution between two independent groups (participants who were persuaded to complete the TIPI and those were not) and a non-normal distributed dependent variable (composite susceptibility scores) [35]. Results indicate that there is no significant difference in the distribution of participants' 
composite susceptibility scores for the Unity principle and the actual effectiveness of the Unity strategy $(U($ Persuaded $=15$, Not - Persuaded $=26)=259, z=1.76$, twotailed,$p=$ $.086, r=.3)$, the Commitment principle and actual effectiveness of the Commitment strategy $(U($ Persuaded $=20$, Not - Persuaded $=16)=172, z=0.388$, twotailed,$p=$ $.718, r=.1)$, the Reciprocity principle and actual effectiveness of the Reciprocity strategy $(U($ Persuaded $=38$, Not - Persuaded $=21)=422, z=0.398$, twotailed $, p=.69, r=.1)$, the Scarcity principle and actual effectiveness of the Scarcity strategy (U(Persuaded= 13$, Not - Persuaded $=19)=127.5, z=0.160$, twotailed, $p=.88, r=0)$ and the Social proof principle and Social proof strategy $(U$ (Persuaded $=27$, Not - Persuaded $=$ $24)=332.5, z=0.161$, twotailed $, p=.872, r=0)$. However, an analysis of the distribution of susceptibility scores and whether participants' were persuaded to complete the TIPI test or not (actual effectiveness irrespective of persuasive strategy received), indicates a significant difference in susceptibility scores amongst participants for Unity $(U($ Persuaded $=160$, Not - Persuaded $=142)=13109.5, z=2.352$, twotailed,$p=$ $.019, r=.1)$, Scarcity $(U($ Persuaded $=160$, Not - Persuaded $=142)=12994.5, z=$ -2.219$, twotailed $, p=.027, r=.1)$ and Social proof $(U($ Persuaded $=160$, Not Persuaded $=142)=12898.5, z=2.04$, twotailed $, p=.04, r=.1)$ but not for Reciprocity $U($ Persuaded $=160$, Not - Persuaded $=142)=11730, z=0.521$, twotailed $, p=.602, r=$ $0)$ or Commitment $(U$ (Persuaded $=160$, Not - Persuaded $=142)=12095, z=$ 0.995 ,twotailed, $p=.320, r=1)$. This suggests that participants with greater composite susceptibility scores for Unity, Scarcity and Social proof were more likely to be persuaded to complete the TIPI test.

We investigated whether there was any significant difference in the distribution of composite susceptibility scores and participants' gender and age respectively. This was in order to discover whether participants' susceptibility to persuasion varied based on individual differences. Excluding participants who choose not to indicate their gender during our study, results from a Mann-Whitney U test indicate that there is a significant difference in the distribution of composite susceptibility scores for the Social proof principle and participants' gender $(U($ Female $=123$, Male $=178)=12578, z=$ 2.212 ,twotailed, $p=.027, r=.1$ ). This suggests that Male participants reported greater susceptibility to the Social proof strategy, compared to Female participants. There was no significant difference in the distribution of participants' composite susceptibility scores and participants' gender for the Unity principle $(U($ Female $=123$, Male $=$ $178)=10607.5, z=-0.466$, twotailed, $p=.642, r=0)$, Reciprocity $(U($ Female $=$ 123$, Male $=178)=11019, z=0.103$, twotailed $, p=.918, r=.1)$, Scarcity $(U($ Female $=$ 123$, Male $=178)=11936, z=1.37$, twotailed, $p=.171, r=.1)$ and Commitment principle $(U($ Female $=123$, Male $=178)=9829, z=-1.544$, twotailed, $p=.123, r=.1)$.

We investigated the impact of age on the distribution of composite susceptibility scores using a Kruskal-Wallis test, which is suitable for measuring a non-normally distributed dependent variable (composite susceptibility score) across multiple groups (age bands) [35]. Results indicate that there is no significant difference in the distribution of composite susceptibility scores for the Unity principle, $(H(5)=1.452, p=.919)$, Reciprocity $(H(5)=5.514, p=.356)$, Scarcity $(H(5)=1.872, p=.867)$, Commitment $(H(5)=0.370, p=.996)$ and the Social proof principle $(H(5)=8.401, p=.135)$.

\subsection{Limitations}

One of the limitations of this study, centres on how there are a greater number of questions for Unity, compared to all other principles, including Social proof. We accepted 
this trade off as we sought to provide participants with scenarios that included potential overlapping of behavioural determinants related to Unity and Social proof, as part of our research objective to discover susceptibility measures to both, respectively.

With regards to measuring actual effectiveness during our study; while we assume participants who completed the TIPI were persuaded to do so, by stating that this section was optional and then applying a randomly selected persuasive strategy, we cannot rule out entirely that participants who completed the TIPI were motivated to so for reasons outside our study design. Furthermore, our analysis of susceptibility and actual effectiveness is limited due to the sample being divided by those who completed the TIPI and based upon which of the seven persuasive strategies they received. This resulted in a low number of participants (who completed the TIPI) for each strategy, which limits our analysis and results for this part of the study.

\section{Conclusion}

In this paper, we investigated how we can distinguish susceptibility measures to persuasive strategies based on Unity and Social proof, together with other Cialdini [5] principles. Results from our exploratory study indicate that while we are able to distinguish susceptibility measures for Unity and Social proof, together with Commitment, Scarcity and Reciprocity, with acceptable to good internal consistency, we are unable to measure these together with susceptibility to Authority and Liking. While the persuasive strategies for encouraging participants to complete the optional TIPI test, differ in actual effectiveness, there appears to be no significant impact of individual differences amongst the participants, based on age and gender. There was also no significant difference in participants' susceptibility to persuasion and the actual effectiveness for each individual strategy, although it appears that participants with greater susceptibility to Unity, Social proof and Scarcity, were more likely to complete the TIPI, irrespective of which strategy was received. We also discovered that male participants reported greater susceptibility to Social proof, compared to female participants. There was no significant impact of participants' age and susceptibility to persuasion.

In future work, we aim to build on our findings reported in this paper, by investigating how to extend our five component solution to incorporate measures of susceptibility to Liking and Authority. We also intend to investigate potential overlaps and similarities between other Cialdini [5] principles of persuasion, to discover how we can account for these and whether it is possible to develop susceptibility measures to persuasive strategies consisting of different combinations of Cialdini [5] principles. We believe this work can further help to design personalised persuasive strategies, taking into consideration overall susceptibility to different strategies, different combinations of strategies together with individual differences.

\section{References}

1. Bell, M., Chalmers, M., Barkhuus, L., Hall, M., Sherwood, S., Tennent, P., Brown, B., Rowland, D., Benford, S., Capra, M., et al.: Interweaving mobile games with everyday life. In: Proceedings of the SIGCHI conference on Human Factors in computing systems. pp. 417-426. ACM (2006)

2. Beun, R.J.: Persuasive strategies in mobile insomnia therapy: alignment, adaptation, and motivational support. Personal and Ubiquitous Computing 17(6), 1187-1195 (2013) 
3. Borges, S.S., Durelli, V.H., Reis, H.M., Bittencourt, I.I., Mizoguchi, R., Isotani, S.: Brazilian portuguese cross-cultural adaptation and validation of the susceptibility to persuasion scale (br-stps). In: 2017 IEEE 17th International Conference on Advanced Learning Technologies (ICALT). pp. 72-73. IEEE (2017)

4. Chittaro, L.: Tailoring web pages for persuasion on prevention topics: Message framing, color priming, and gender. In: International Conference on Persuasive Technology. pp. 3-14. Springer (2016)

5. Cialdini, R.: Pre-suasion: A revolutionary way to influence and persuade. Simon and Schuster (2016)

6. Ciocarlan, A., Masthoff, J., Oren, N.: Actual persuasiveness: impact of personality, age and gender on message type susceptibility. In: International Conference on Persuasive Technology. pp. 283-294. Springer (2019)

7. Field, A., Miles, J., Field, Z.: Discovering statistics using r (2012)

8. Flora, D.B., Curran, P.J.: An empirical evaluation of alternative methods of estimation for confirmatory factor analysis with ordinal data. Psychological methods 9(4), 466 (2004)

9. Gadermann, A.M., Guhn, M., Zumbo, B.D.: Estimating ordinal reliability for likert-type and ordinal item response data: a conceptual, empirical, and practical guide. Practical Assessment, Research \& Evaluation 17(3) (2012)

10. Gosling, S.D., Rentfrow, P.J., Swann Jr, W.B.: A very brief measure of the big-five personality domains. Journal of Research in personality 37(6), 504-528 (2003)

11. Hair, J.F., Black, W.C., Babin, B.J., Anderson, R.E.: Multivariate data analysis: Pearson new international edition. Pearson Higher Ed (2013)

12. Hauser, J.: Gl urban, g. Liberali, and M. Braun. Website morphing. Marketing Science 28(2), 202-223 (2009)

13. Herrmanny, K., Ziegler, J., Dogangün, A.: Supporting users in setting effective goals in activity tracking. In: International Conference on Persuasive Technology. pp. 15-26. Springer (2016)

14. Horn, J.L.: A rationale and test for the number of factors in factor analysis. Psychometrika 30(2), 179-185 (1965)

15. Kaiser, H.F.: The application of electronic computers to factor analysis. Educational and psychological measurement 20(1), 141-151 (1960)

16. Kaptein, M.: Adaptive persuasive messages in an e-commerce setting: the use of persuasion profiles. European Conference on Information Systems (ECIS) (2011)

17. Kaptein, M., De Ruyter, B., Markopoulos, P., Aarts, E.: Adaptive persuasive systems: A study of tailored persuasive text messages to reduce snacking. ACM Trans. Interact. Intell. Syst. 2(2), 10:1-10:25 (Jun 2012). https://doi.org/10.1145/2209310.2209313, http://doi.acm.org/10.1145/2209310.2209313

18. Kaptein, M., Halteren, A.: Adaptive persuasive messaging to increase service retention: using persuasion profiles to increase the effectiveness of email reminders. Personal and Ubiquitous Computing 17(6), 1173-1185 (2013)

19. Kaptein, M., Markopoulos, P., De Ruyter, B., Aarts, E.: Personalizing persuasive technologies: Explicit and implicit personalization using persuasion profiles. International Journal of Human-Computer Studies 77, 38-51 (2015)

20. MacCallum, R.C., Widaman, K.F., Zhang, S., Hong, S.: Sample size in factor analysis. Psychological methods 4(1), 84 (1999)

21. Oinas-Kukkonen, H., Harjumaa, M.: Persuasive systems design: Key issues, process model, and system features. Communications of the Association for Information Systems 24(1), $28(2009)$

22. Orji, R.: Design for Behaviour Change: A model driven approach for tailoring Persuasive Technologies. Ph.D. thesis, University of Saskatchewan Saskatoon, SK, Canada (2014)

23. Orji, R.: Persuasion and culture: Individualism-collectivism and susceptibility to influence strategies. In: PPT@ PERSUASIVE.pp. 30-39 (2016) 
24. Orji, R.: Why are persuasive strategies effective? exploring the strengths and weaknesses of socially-oriented persuasive strategies. In: International Conference on Persuasive Technology. pp. 253-266. Springer (2017)

25. Orji, R., Mandryk, R.L., Vassileva, J.: Gender, age, and responsiveness to cialdini's persuasion strategies. In: International Conference on Persuasive Technology. pp. 147-159. Springer (2015)

26. Osborne, J.W., Costello, A.B., Kellow, J.T.: Best practices in exploratory factor analysis. Best practices in quantitative methods pp. 86-99 (2008)

27. Oyibo, K., Adaji, I., Orji, R., Olabenjo, B., Azizi, M., Vassileva, J.: Perceived persuasive effect of behavior model design in fitness apps. In: Proceedings of the 26th Conference on User Modeling, Adaptation and Personalization. pp. 219-228. ACM (2018)

28. Oyibo, K., Adaji, I., Orji, R., Olabenjo, B., Vassileva, J.: Susceptibility to persuasive strategies: A comparative analysis of nigerians vs. canadians. In: Proceedings of the 26th Conference on User Modeling, Adaptation and Personalization. pp. 229-238. ACM (2018)

29. Oyibo, K., Orji, R., Vassileva, J.: The influence of culture in the effect of age and gender on social influence in persuasive technology. In: Adjunct Publication of the 25th Conference on User Modeling, Adaptation and Personalization. pp. 47-52. ACM (2017)

30. Oyibo, K., Orji, R., Vassileva, J.: Investigation of the influence of personality traits on cialdini's persuasive strategies. In: PPT@ PERSUASIVE. pp. 8-20 (2017)

31. Panter, A.T., Swygert, K.A., Grant Dahlstrom, W., Tanaka, J.S.: Factor analytic approaches to personality item-level data. Journal of personality assessment 68(3), 561-589 (1997)

32. Parsons, K., Butavicius, M., Delfabbro, P., Lillie, M.: Predicting susceptibility to social influence in phishing emails. International Journal of Human-Computer Studies 128, 17-26 (2019)

33. Pratkanis, A.R., Pratkanis, A., Aronson, E.: Age of propaganda: The everyday use and abuse of persuasion. Macmillan (2001)

34. Raubenheimer, J.: An item selection procedure to maximize scale reliability and validity. SA Journal of Industrial Psychology 30(4), 59-64 (2004)

35. Siegel, S.: Nonparametric statistics for the behavioural sciences. McGraw New York NY US (1956)

36. Stibe, A., Cugelman, B.: Persuasive backfiring: when behavior change interventions trigger unintended negative outcomes. In: International Conference on Persuasive Technology. pp. 65-77. Springer (2016)

37. Tajfel, H.: Individuals and groups in social psychology. British Journal of Social and Clinical Psychology 18(2), 183-190 (1979)

38. Tajfel, H., Turner, J.C., Austin, W.G., Worchel, S.: An integrative theory of intergroup conflict. Organizational identity: A reader pp. 56-65 (1979)

39. Tajfel, H.E.: Differentiation between social groups: Studies in the social psychology of intergroup relations. Academic Press (1978)

40. Thomas, R.J., Masthoff, J., Oren, N.: Adapting healthy eating messages to personality. In: International Conference on Persuasive Technology. pp. 119-132. Springer (2017)

41. Velicer, W.F.: Determining the number of components from the matrix of partial correlations. Psychometrika 41(3), 321-327 (1976)

42. Vonnegut, K.: Cat's cradle. Penguin (1964)

43. Wais-Zechmann, B., Gattol, V., Neureiter, K., Orji, R., Tscheligi, M.: Persuasive technology to support chronic health conditions: investigating the optimal persuasive strategies for persons with copd. In: International Conference on Persuasive Technology. pp. 255-266. Springer (2018)

44. Wall, H.J., Campbell, C.C., Kaye, L.K., Levy, A., Bhullar, N.: Personality profiles and persuasion: An exploratory study investigating the role of the big-5, type d personality and the dark triad on susceptibility to persuasion. Personality and Individual Differences 139, 69-76 (2019)

45. Zumbo, B.D., Gadermann, A.M., Zeisser, C.: Ordinal versions of coefficients alpha and theta for likert rating scales. Journal of modern applied statistical methods 6(1), 4 (2007) 